\title{
Use Auto-Regressive Distributed Lags Models (ARDL) to Predict Inclusive Growth in Jordan in $2003-2017$
}

\author{
Dr. Mohammad Alalaya
}

Dr. Mohammad, Almahameed

AlHusien Bin Talal University

Jordan

\begin{abstract}
This paper utilizes of auto regression distributed lag model to analyze the inclusive growth in Jordan for the period 2003-2017, the paper provides an empirical analysis of the relationship between inclusive growth through the determinants variables which suggested that these affected variables. The ARDL model testing the dynamic short - run and long - run, the error correction method ECM to investigate the long - run. AiC is chosen as lag length, also bound test meth has been used, the cointegration test, and (ECM) error correction method supported by diagnostic test results. The finding of this study indicates that there is a positive effect of inflation and population growth on inclusive grow in Jordan, also the FDI has a negative relationship in the short - run, but significantly positive contribution to inclusive grow in long - run.
\end{abstract}

Keywords: ARDL, Inclusive growth, ECM, Cointegration, Jordan).

\section{Introduction: section one}

In financial application, we use a dynamic regression model for available (Y) includes lagged value, including (y) variable itself, as explanatory variables for the response $\mathrm{Yt}$ at time An analysis of long-run relations as econometric analysis, has been focused on both empirical research and theoretical in economics. Also, we can trend the series and model this process as stationary distributed lags, which can be abbreviated as ARDL model (Pagar \& Sargan, 1984). And it becomes more complicated when the variables are difference -stationary level or integrated of order shin, 1995), in their paper, they examined the use of traditional ARDL approach for the use of long-run relations, and they considered the general ARDL (p, q) model. The estimator of the short -run parameters $\mathrm{a}_{0}, \mathrm{a}_{1}, \mathrm{~B}, \mathrm{~B}^{*}, \ldots \ldots \mathrm{B}^{*}{ }_{\mathrm{q}-1}$, and $\mathrm{v} \phi=\left(\phi_{1} \mathrm{r} \ldots \ldots \phi\right)$ are $\sqrt{T-\text { consistent }}$, and the covariance matrix of these estimators has a well-defined unit which is asymptotical, the degree of augmentation which required depends on whether $\mathrm{q} \geq \mathrm{s}+1$ or not. Donating the contemporaneous correlation between $\mathrm{U}_{\mathrm{t}}$ and $\in t$ by the $\mathrm{k} * 1$ vector $\mathrm{d}$. The lag distributed function gives a magnitude of the coefficient of a lagged explanatory variable, estimation and inference concerning the long-run properties of the model, which carried out, by using standard asymptotic theory (Kennedly, 1998). Mitchel and Speaker, 1986, have introduced a model via a linear transformation of the polynomial lag model, estimated as reduced form parameters, and recovered estimate the structural parameters via an inverse nonlinear estimation transformation of the reduced form. Kim, Eraser \& Hyndman 2010, estimated the long-run response which is often extremely disparate, Marques and McNelly, 1988, who is sampling variability of the long run response estimator, which from their view is difficult to estimate. However, the multidimensional distributed proposed by Grace Wahba 1969, Lacks a multi-dimensional visualization to illustrate the behavior of the model in economic textbooks, many researchers have calculated the long -run effects, such as Hil et al, 2010, Gujarati and Porter, 2010, Greene, 2012, and Wooldridge , 2012. Some of them calculated the ARDL model long-run effect from a single equation (OLs) and dynamic panel data (DPD) models, but many of the time period. The two normally distributed random model variables which have zero means and independent the ratio result is distributed, Cauchy. Hinkley ,1969 has studied the long -run effect and show the shape of its density which can be unimodal, and both symmetric or asymmetric depending on the value of the coefficient of the many researchers used estimator and applied many different methods as ; indirect inference are used as Jack-knifing method in order to have less bias estimates. 
Other studies as Dahan and Jochmans ,2015. Giroux et al,2010.these papers discussed that Jackknife estimator can remove bias by comparing the maximum likelihood estimate from the full sample with the with the estimates from a subsample.

A basic premise series generally integrated of order 1(d), or difference stationary, these cannot be analyzed by the traditional ARDL. Hence the other method can be used, which are developed by Engle and Granger, 1987, then Johansen, 1998, and Philips and Han sen,1990. This development of the method concerned with analysis long-run relationship between variables integrated with $\mathrm{s}$, which can be described as cointegration method, this means that the series is stationary of some order of difference and the speed of return to equilibrium after deviation is measured by error correction model (ECM), and the cointegration test is not applicable in case of variables that are integrated of different orders. The recent studies suggested that ECM is, between series with a different order of integration, and this procedure can give the short-dynamic (Equivalent)to ARDL, and long-run of relationship.

More recently a search technique has been proposed by who employed in empirical research rational distribution lags, also he has not given a full treatment of the estimation problems of the parameters involved. Where Dhrymar who proposed a technique for the geometric lag distribution which occurring in a relationship characterized by the first order of Markov process in its error term d suggested a method on his study to estimate a consistent and asymptotically efficient of the parameters of a rational distribution lag by use the spectral technique. The DLNMS methodology which previously in Gasparrini, 2014, and Gasparrini et, al 2010, 2017, with a detailed with algebra cal development. In a Gasparini study, we can summaries that the bi-dimensional association can be derived mainly exposure-response at specific predictor value and over cumulative exposureresponse as the net effect across the whole lag period. Hendry and Mizons ,1995, they have used a general model which recommended as a generalization of the first order serial correlation model, which considered as the first order serial autoregressive distributed lag model, a linear dynamic regression model in which Yt years the modeling of economics and financial time series as a multivariate tool linear series as (VAR, SVAR, VECM), and non-linear systems of equations as (MS-VAR), becomes as a standard tools to obtain long-run relation and dynamic relation to avoid such as the lag structure in VAR models. Jacobson,1995, who used on tests on residual autocorrelation, also AIC, Akaike information criterion and BIC, as Winker, 2000, these criteria and approaches did not take into account potential of non- stationary of the time series and the restrictions' which imposed by the rank

Chao and Philips, 1999, they have employed a modified information criterion for the case of partially non stationary VAR models. The lag structure is not considered to consequence of lag up to lag $\mathrm{k}$, but might consist where the dynamic model selection performed taking the resections to reduce rank regression, therefore it's better to use in application SURE -Like- modification as for two-step which can be reduce the rank estimator ( Ahn and Reisel,1990)which proposed in their paper.

The numerical method used in estimation the model for a given dynamic structure to reduce the rank estimation (ML estimators), because more involved in the VEC model, the long-run relationship between the investigated variables is detected through Wald -test (F-static), the advantage of this approach lies in its identification of the cointegration vectors, then there are multiple vectors, this technique is lashed and crashed, if there is presence of integrated stochastic trend of order 1(2). Peitzman,2000. Said that economic theory suggests that no pervasive tendency for prices to respond faster to one kind of cost change than the other, he used ARDL model in his application, he announced that the asymmetric adjustment is fruitful in the application. Many scientists examined the effect of government economic expenditure on economic growth and affected variables through many different methods and models; such as (Rarjan and Sharma,2000)who examined the effect of government expenditure on economic growth, they have got that significant positive impact of government expenditure on economic growth, they also reported that the existence of cointegration among variables . Swaroop and Zou, 1996, examined the relationship between government expenditure and economic growth for a group of developing countries, the results of their study there is a negative association with the growth of real GDP per Capita and showed that reduced as expenditure is positively related to real GDP per Capita. Skathivel and Yadav, 2005, studied the relationship between government expenditure for India and economic growth, their conducted study results show that it was that bi-directional causality exists between national income and public expenditure, where Liu et, al, 2008, studied the same relation to the U.S.A data during 1947-2002, the results show that public expenditure impact well $\mathrm{s}$ the economic growth, and they have tested the Keynesian hypothesis which exists more influence the Wagner law in the U.S.A. 
Many authors have the positive effects in economic growth as, Abu and Abdullahi ,2010, who conduct their study variables as government spending on agriculture, education ,defense, health, and transportation sector the results of the study is that the Nigerian economy has a negative effect which still reviled stamping the relationship between government expenditure and economic growth. Komain and Brahmassrene, 2007, studied the association between government expenditure and economic growth in Thailand, they have used Granger causality test, their results indicate that there are significant positive effects of government spending on economic growth.

\section{Section two: framework, notes about Jordan indicators:}

Inclusive growth that not only creates economic opportunities also ensures equal access to the opportunities created for all segments (Ali I, Zhaungj, 2007). Several definitions for identification inclusive growth, but still remain rather ambiguous as the term because still there is no universal definition but some definition as It is the type of growth that only creates new economic opportunities (Asian development bank). The world bank defines the inclusive growth as the pace and pattern of economic growth which are linked and assessed together with aim of reducing Absolute poverty the framework of this study, even the determinant variables which affected the inclusive growth depends on a diagram of the world development index model, which declare blow as figure (1).

Figure (1): Theoretical model of inclusive growth

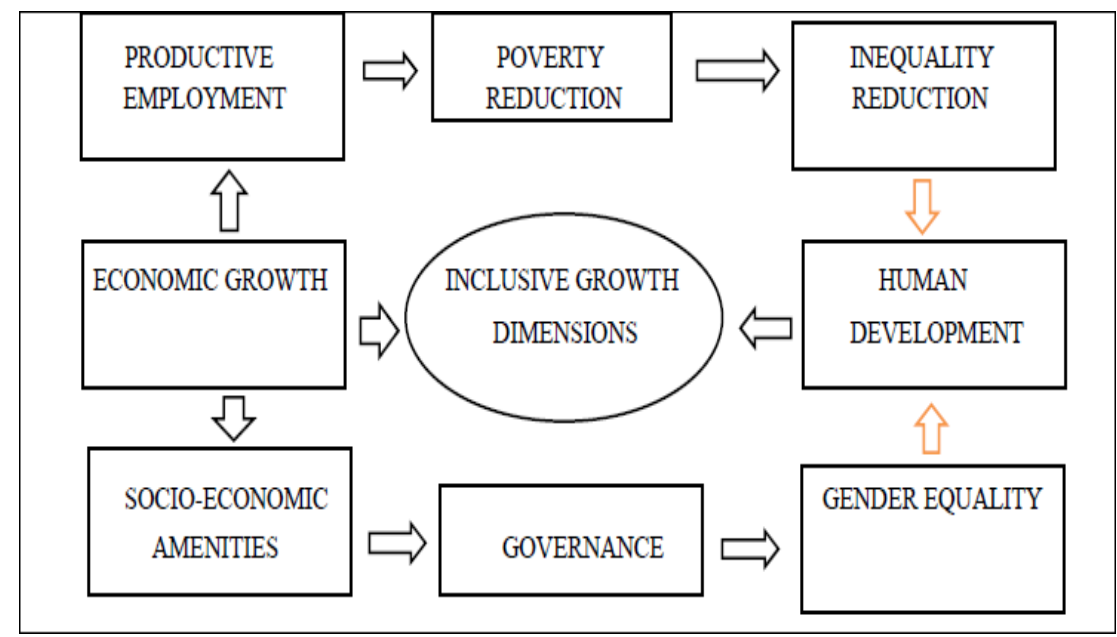

Source: world development index

The indicator for Jordan indicates that Jordan becomes rank 95 from 187 countries, in the middle of the human development index. transparency 56, Gini coefficient is 0.337 , and the global gender gap report is not so well as 117 from 135 countries, this appears in the table (1), below.

Table ( 1 ): INDICATORS FOR JORDAN, 2016

\begin{tabular}{|lr}
\hline Human Development Index & $95 / 187$ \\
\hline Global Competitiveness Report & $65 / 139$ \\
\hline $\begin{array}{l}\text { Transparency International Corruption } \\
\text { Perceptions Index }\end{array}$ & $56 / 182$ \\
\hline Life expectancy at birth & 73.4 \\
\hline Gini coefficient & 0.377 \\
\hline Freedom House Index (Internet) & Partly free \\
\hline Freedom House Index (Press) & Not free \\
\hline Global Gender Gap Report & $117 / 135$ \\
\hline
\end{tabular}

Source: Atlas of Jordan poverty and poverty reduction - DOS- poverty survey 2017. 
This study can be highlighted the need to address three problems faced the Jordanian economy one of them to improve its inclusiveness and to have new economic thoughts about unemployment, inequality, and poverty, these three problems the government failed to tackle them beyond other problems such as CPI, inflation,.....

\section{1- Inequalities :}

The large income disparity in Jordan is seen to have worsened results among the study period, due to unavailability of jobs and the inaccessibility of credit and financing the Gini index which measures the inequality as compared was measured 0.37 in 2017, figure (2) shows the Gini coefficients .

\section{Figure (2): Gini Coefficient for Jordan}

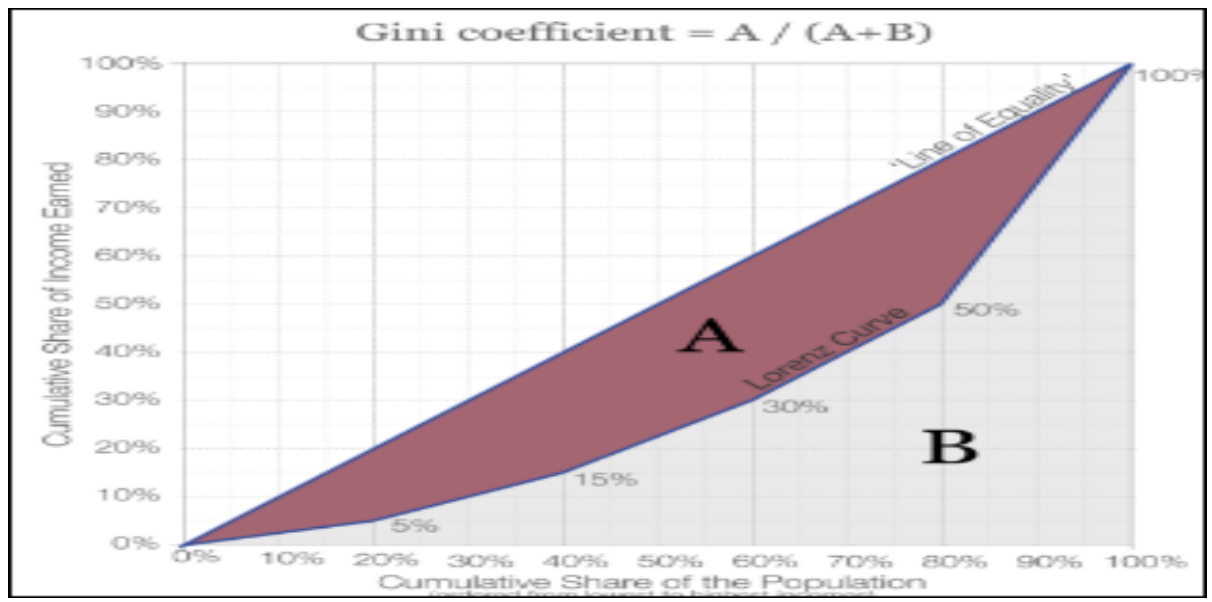

Source: Atlas of Jordan poverty and poverty reduction - DOS- poverty survey 2016.

\section{2- Poverty:}

In 2017 both rural and urban of the country suffering from the high prices and cost of living, the poverty measured by headcount ratio worsened in the geographical district of the country. Jordan is one of the poorest countries with over 8 million inhabitant and 3 million immigration people from other countries, due to war between $25 \%$ - $34 \%$ population are living below the poverty line this due to many factors increase this problem such as:

1- Higher price of oil and energy also price of electricity consumption.

2- Fixed salaries since 2000 and declining with real income.

3- Socio-cultural conditions.

4- Jobless a noninclusive growth.

5- Inequality and unemployment.

6- Macroeconomic conditions which are affected by the Jordanian economy.

7- Field of economic policy which can be described as policy shocks.

Figure (3) illustrated the poverty state in Jordan.

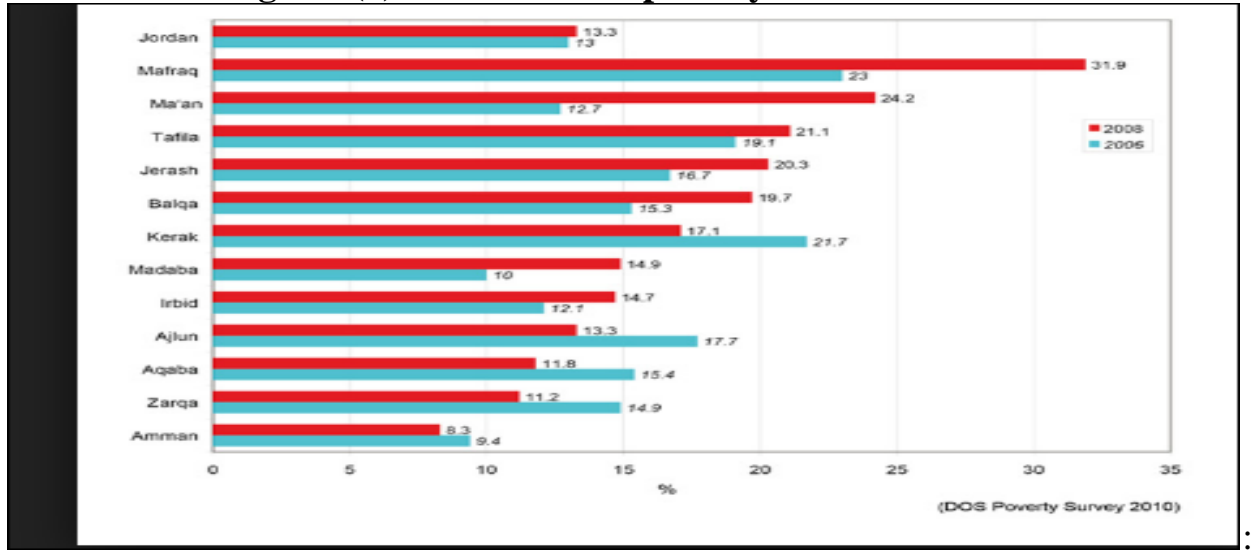

Source: Jordan poverty and poverty reduction strategy, final report, UNDP-and DOS- poverty survey 2010 


\section{3- Unemployment:}

In Jordan economy the growth rate of labor force is higher than demand, hence the labor force supply is greater than needs in many fields of works market this the output of labor force does not match the market needs with underemployment situation much more than outright unemployment out-ripped the magnitudes the figure (4), and (5), shows this problem which becomes in 2017 18.4\%.

Figure (4): Unemployment rate and the poverty rate for Jordan

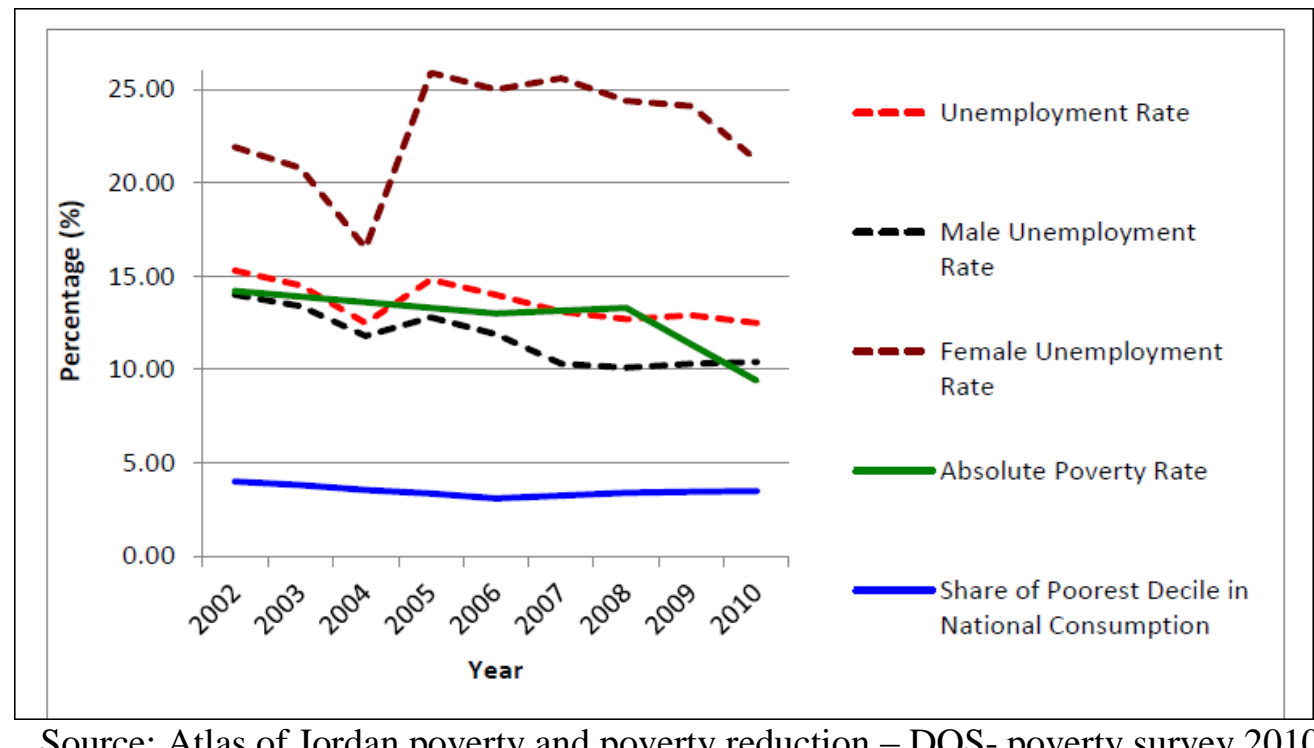

Source: Atlas of Jordan poverty and poverty reduction - DOS- poverty survey 2010

Figure (5): Unemployment rate during Jul 2015- Jan 2018

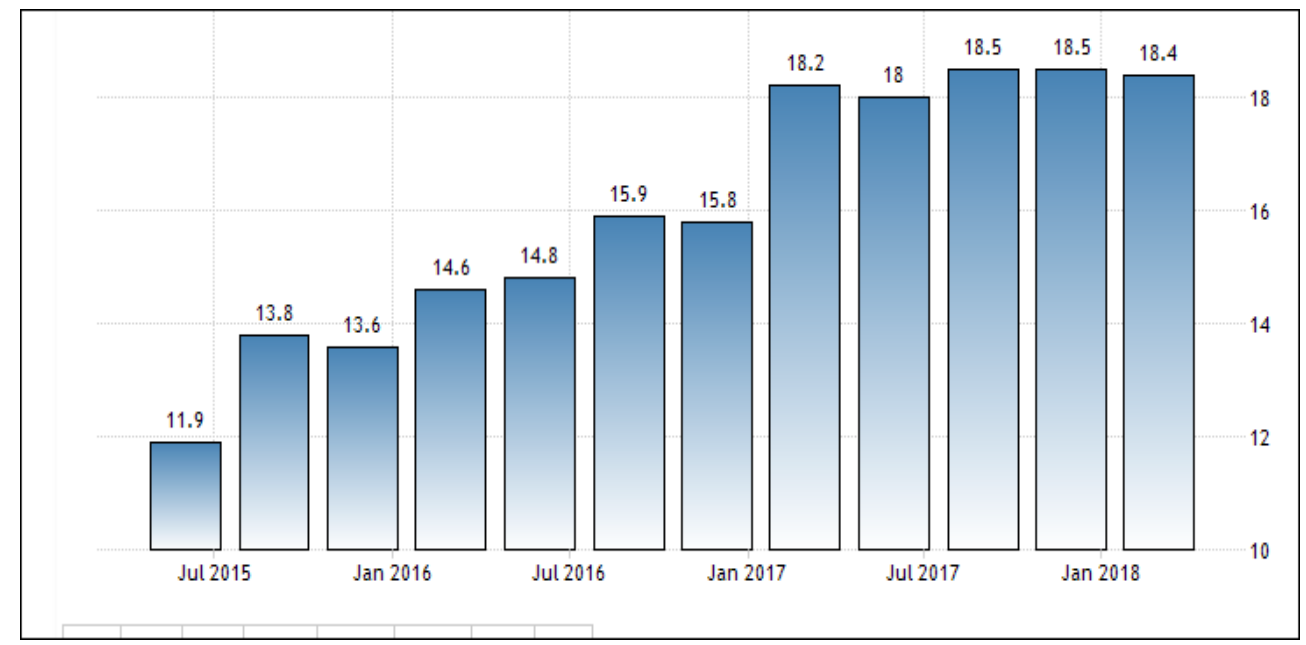

Source: Section Three: Theoretical Approach:

1-3 : Estimation of likelihood function: As the equilibrium correction model, it is helpful to first consider the first order serial autoregressive distributed lag model. The equation can be as:

$\mathrm{Y}_{\mathrm{t}}=\frac{\mathrm{t}}{\mathrm{t}-1} \Delta \mathrm{Y}_{\mathrm{t}}+\frac{\mathrm{B}_{\mathrm{i}}+\mathrm{V}_{2}}{1-\mathrm{t}} \mathrm{Xt}-\frac{\mathrm{B}_{2}}{1-\mathrm{t}} \Delta \mathrm{t}=\mathrm{t}^{\prime} \Delta \mathrm{Y}_{\mathrm{t}}+\mathrm{B}_{2}^{*} \Delta \mathrm{Xt}\left(\mathrm{t} \frac{1}{1-\mathrm{t}} 4 \mathrm{t}\right)$

This equation represents the short-run dynamics, also it shows us how the equation can be approached. B ${ }_{1}^{*}$

presents the long -run effects of $\mathrm{Y}$ with respect to $\mathrm{X}$, while $\mathrm{B}_{2}^{*}$ reflects the short rum or the response of $\mathrm{Y}$ to the changes in X (Wickens and Breusch, 1988), Therefore many econometric methods should be available such as cointegration method, Gerena lag model likelihood function estimation, Granger causality, ect.... 
The way to estimate the series data of the static model, the first order serial, and the first order autocorrelation models, which considered as the autoregressive distributed lag models. Many researchers said that the OLS estimator remains consistent, but the OLS estimator loses its property due to the inclusion of serial lagged of dependent variable among the regresses. Also, its consistency can cause the loose of the property of un baseness, this lets many researchers suggest that maximum likelihood can solve this problem to become over this problem, (Anselin and Hudak, 1992). When we estimate the series data by OLS conditional and ML method, it also is possible to obtain unconditional results. In the same time, we can test the serial with restricted test and LM (Lagrange Multiplier) test. The regression equation includes variables lagged one period in time are often estimate OLS conditional when we estimate the model by LM it's possible to have unconditional (results the unconditional log-likelihood function of the general first order serial and autoregressive lad model (Anselin, 1988).

$$
\log \mathrm{f}_{\mathrm{y}} \mathrm{Y}_{\mathrm{t}-1} \ldots . . . \mathrm{y}_{2} \mid \mathrm{y}_{1}=-\frac{1}{2} \mathrm{n}(\mathrm{T}-1) \log \left(2 \eta \sigma^{2}\right)+(\mathrm{T}-1) \log (1-\sigma \mathrm{w}) 1-\frac{1}{2 \sigma^{2}} \sum_{\mathrm{t}-2}^{\mathrm{T}} e_{t}, e_{t}
$$

To obtain the unconditional log-likelihood function, we should rewrite the first order serial and auto distributed lag model, which can be performed in one period as:

$$
\left.\log \mathrm{f}_{\mathrm{t}} \mathrm{Y}_{\mathrm{t}-1} \ldots \ldots \mathrm{y}_{2} \mid \mathrm{y}_{1}=-\frac{1}{2} \mathrm{n}(\mathrm{T}-1) \log \left(2 \eta \sigma^{2}\right)+(\mathrm{T}-1) \log (1-\sigma \mathrm{w}) 1-\frac{1}{2 \sigma^{2}} \sum_{\mathrm{t}-2}^{\mathrm{T}} e_{t}, e_{t} \ldots \ldots \ldots . .3 \quad\right)
$$

To obtain the unconditional log-likelihood function, we should rewrite the first order serial and auto distributed lag model, which can be performed in one period as:

$$
\mathrm{B}_{\mathrm{t}-\mathrm{m}}=\mathrm{B}_{\mathrm{x}}+Q y_{t-(m+1)}+U_{t-(m+1)}
$$

When we substitute $\mathrm{y}_{\mathrm{t}-1}$ to the equation the equation becomes as :

$$
\mathrm{B} \mathrm{y}_{\mathrm{t}}=\left(\mathrm{B}_{\mathrm{x}}+U_{t}\right)+\mathrm{AB}^{-1}\left(\mathrm{BX}+U_{t-1}\right)+\left(\mathrm{AB}^{-1}\right)^{2}\left(\mathrm{BX}+U_{t-2}\right)+\ldots \ldots+\left(\mathrm{AB}^{-1}\right)^{\mathrm{m}} \mathrm{BX}+(\mathrm{AB}-1)^{\mathrm{m}} \mathrm{AY} \mathrm{t}_{-(\mathrm{m}+1)} \ldots \ldots \ldots \ldots \text { (5) }
$$

\section{2-3 : Dynamic model effect of temporary and permanent changes:}

The optimization method has been to work extremely by finding the relevant lags for all replications and including a small number of additional lags to have a simple dynamic structure. The whole method to have the standard method has to include all number of lags in order to capture the relevant lags and this approach indicates a slight tendency of over fitting for the take all up. As (Green holland Karlsson, 1999), we might conclude that choosing the lag length in VAR-model is not an easy task. It is remarkable that the optimization heuristic Seems to identify these lags allowing for correct estimation of the co integration rank (Peter Winker et al., 2004). We can use many dynamic panel data (DPD) as an estimator to estimate model of long-run effects, such as the GMM system SG MM), Anderson - Hsaio (AH), and difference GMM) (DGMM) and results of these estimators can be noticed as: The 90\% empirical sample range of LPR values long run propensity; the median estimated LPR value, and lastly the type I error rates (Estimation of long-run effects in the ARDL model). The Monte Carlo experiments add an explanatory variable to the data generating process (DGP) Equation:

$$
\begin{aligned}
& \mathrm{Y}_{\mathrm{t}}=1+\mathrm{B}_{\mathrm{x}} \mathrm{X}_{\mathrm{t}}+\mathrm{B}_{\mathrm{y}} \mathrm{Y}_{\mathrm{t}-1}+\mathrm{U}_{\mathrm{t}} ; \mathrm{t}=1,2, \ldots, \mathrm{T}_{\mathrm{y}}, \mathrm{U}_{\mathrm{t}} \sim \mathrm{NiD}(\mathrm{O}, 1) . \\
& \mathrm{B}_{\mathrm{x}}=1, \mathrm{~B}_{\mathrm{y}} \text { takes value } 1,11,2,10,20 \text { and } 100 \text { where }
\end{aligned}
$$

$$
\text { value estimated LRP value can be Calculated by } \hat{B}_{x} /\left(1-\hat{B}_{y}\right) \text {. }
$$

Sometimes with Mont Carlo experiments substantial biases in the LRP stimates can appear, also again an evident for large values of $\mathbf{B}_{\mathbf{y}}$ median of the estimator DGMM, SGMM and AH. Results are rendering but the large values appear well of $\mathbf{B}_{\mathbf{y}}$ in even worse performance, enhance the size distortions are apparent again beyond the substantial biases for large values of $\mathbf{B}_{\mathbf{y}}$.

\section{3-3 : Jackknifing and Indirect inference:}

These are two methods that are suggested for correcting the bias associated with estimating ARDL model in finite samples or obtain less biased estimations of $\mathbf{B}_{\mathbf{y}}$ the Jackknife estimator removes the bias by comparing the maximum - likelihood estimate from the full sample with estimates calculated from subsamples the method is to 
divided the full sample into two subsample and then to estimate both of them, as let $\hat{\mathrm{B}} \frac{1}{2}=0.5\left(\hat{\mathrm{B}}_{\mathrm{s} 1}+\hat{\mathrm{B}}_{\mathrm{se}}\right)$ and then compared to the full sample data estimator the jackknifed estimator $\hat{B} \frac{1}{2}$ will have smaller bias the other method which can remove the bias is the indirect inference, which can be considered as a simulation-based method for bias reduction the (DGP) process takes the form:

$\mathrm{Y}_{\mathrm{t}}=\mathrm{f}\left(\mathrm{Y}_{\mathrm{t}-1}, \mathrm{X}_{\mathrm{t}} / \theta\right), \quad \theta$ is a vector of $(\mathrm{B}, \sigma), \quad \mathrm{B}$ : is the regression coefficients and $\sigma:$ is the regression error term this method based on three steps, the first step carried out in generating a sequence of random errors of length $\mathrm{T}$ from the $\mathrm{F}$ distribution conditional or estimated $\theta$. Where step 2 chooses values for the parameters of vector $\mathrm{B}$ using $\left.\sum \mathrm{Xt}\right|^{\mathrm{T}} \mathrm{t}=1$ and simulated errors in step $1 \zeta \hat{\mathrm{Y}}_{\mathrm{t}}(\mathrm{B})_{\mathrm{t}}^{\mathrm{T}}=1$ the values are used to calculate an estimate of B , $\sigma$ (B) then in step 3 we repeat step 1 and $2 \mathrm{M}$ times (M simulation) for a given set of B values the bias-reduced estimator is obtained. Both methods jackknifing and indirect inference are effective at reducing the bias associated with estimating $\mathbf{B}_{\mathbf{y}}$ even when the $\mathrm{JK}$ and indirect inference is a testimony to the effectiveness of the procurers to reduce finite sample bias.

\section{Section Four: Models, Variables, and methodology of the Study:}

Greene (2003), Gujarati, 2004; Hih et al., 2003, the DL model with P lags and just on explanatory variable X may be given by (1), with $\mathrm{P}$ being the lag size of $\mathrm{X}$, the model can be expressed as: $\mathrm{Y}_{\mathrm{t}}=Q+\sum_{\mathrm{i}=0}^{\mathrm{p}}\left(\mathrm{B}_{\mathrm{i}} \mathrm{X}_{\mathrm{t}-\mathrm{i}}\right)+\mathrm{U}_{\mathrm{t}}$

the errors $\mathrm{U}_{\mathrm{t}}$ in the equation are assumed to be iid $\mathrm{N}\left(0, \sigma^{2}\right)$ variables the choice between two regression submodels that would explain the most part of variation observed in the response $\mathrm{Y}$ the usual coefficient of determination $\mathrm{R}^{2}$ is not adequate, and it may be increased solely due to an increase of regressors. The $\mathrm{R}^{2}$ can be calculated as:

$$
\mathrm{R}^{2}=1-\frac{\mathrm{n}-1}{\mathrm{n}-\mathrm{k}-1}\left(1+\mathrm{R}^{2}\right)=1-\frac{\mathrm{n}-1 \text { SSE }}{\mathrm{n}-\mathrm{k}-1 \text { SST }}
$$

the final prediction error FPE (Akaike, 1969 is an estimate of the asymptotic by the following equation:

$$
\mathrm{F} \& \mathrm{E}=\frac{\mathrm{n}+\mathrm{k}}{\mathrm{n}-\mathrm{k}} \hat{\sigma}^{2}
$$

The traditional ARDL (p, q) model as :

$$
\begin{aligned}
& \mathrm{Y}_{\mathrm{t}}=\mathrm{a}_{0}+\mathrm{a}_{1} \mathrm{t}+\sum_{\mathrm{i}=1}^{\mathrm{p}} \varphi_{\mathrm{i}} \mathrm{Y}_{\mathrm{t}-\mathrm{i}}+\mathrm{R}_{\mathrm{t}}^{\prime} \mathrm{X}_{\mathrm{t}}+\sum_{\mathrm{i}=0}^{\mathrm{q}} \mathrm{B}_{\mathrm{t}}^{1} \Delta \mathrm{X}_{\mathrm{t}-1}+\mathrm{U}_{\mathrm{t}} \Delta \mathrm{X}_{\mathrm{t}}=\mathrm{P}_{1} \Delta \mathrm{X}_{\mathrm{t}-1}+\mathrm{P}_{2} \Delta \mathrm{X}_{\mathrm{t}-2} \\
& +\ldots . . \mathrm{P}_{\mathrm{s}} \Delta \mathrm{X}_{\mathrm{t}-3}+\mathrm{et}
\end{aligned}
$$

$\mathrm{U}_{\mathrm{t}}$ and $\mathrm{e}_{\mathrm{t}}$ are serially uncorrelated disturbances with Zero mean 3 and constant variance-covariance, $\mathrm{X}_{\mathrm{t}}$ is the $\mathrm{K}$ dimensional 1 (1) variables the roots of vectors autoregressive process in $\Delta X_{t}$ is stable $P_{i}$ are $K * K$ coefficient matrix. The ARDL augmented version can be written as:

$$
\mathrm{Y}_{\mathrm{t}}=\mathrm{Q}_{0}+\mathrm{a}_{1} \mathrm{t}+\sum_{\mathrm{i}=1}^{\mathrm{p}} \varphi_{\mathrm{i}} \mathrm{Y}_{\mathrm{t}-1}+\mathrm{B}^{\prime} \mathrm{X}_{\mathrm{t}}+\sum_{\mathrm{i}=0}^{\mathrm{m}-1} \Pi_{\mathrm{i}}^{1} \mathrm{X}_{\mathrm{t}-\mathrm{i}}+\eta_{\mathrm{t}}
$$

Where $\mathrm{m}=\max (\mathrm{q}, \mathrm{s}+1), \Pi_{\mathrm{i}}=\mathrm{B}_{\mathrm{i}}^{*}-\mathrm{P}_{\mathrm{i}}^{1} \mathrm{~d}$ the matrix. The ARDL - AIC and the ARDL estimators have very similar small performances. In the majority of experiments the ARDL-SC- in better performance; and it can be expressed when combining with the $\Delta$ method of computing the standard errors of the long - run parameters.

Dominates the Phillips Hansen estimator in small samples where in two steps estimation indicates that Mont Carlo results pointed in favor to this method irrespective of endogenous regressor in our consideration of the 
model of whether the regressors are to be $1(1)$ or $1(0)$. Therefore the general model which considered to be used in this study can be the as the following equation: GDPPPE $=\mathrm{a}_{0}+\mathrm{a}_{1}$ GDPPCT $+\mathrm{a}_{2} \mathrm{Edu}+\mathrm{B}_{3} \mathrm{FDi}+\mathrm{B}_{4}$ GGFCE $+\mathrm{B}_{8}$ GFC

$+\mathrm{B}_{6} \mathrm{INF}+\mathrm{B}_{7} \mathrm{POP} \mathrm{e}_{1}+\mathrm{B}_{8} \mathrm{TOP}+\mathrm{e}_{\mathrm{t}} \ldots \ldots$

where: TOP: Trade openness, FDI foreign direct investment, Educ: education expedition, GFCF: gross fixed capital formation, POPG: Population growth rate GGFCE: government financial consumption expenditure.

$\mathrm{Y}_{\mathrm{i}}^{*}=\mathrm{a}_{0}+\mathrm{a}_{1} \overline{\mathrm{Y}}_{\mathrm{t}}+\mathrm{B}_{2} \mathrm{Y}_{\mathrm{t}}+\Sigma_{\mathrm{t}}$

$\mathrm{Y}_{\mathrm{t}}^{*}$ Indicates to inclusive growth in Jordan which can be measured by the GDP per person employed (as productive employment) $\mathrm{Y}_{\mathrm{t}}$ is the initial level of income.

2-3: The Methodology:

Depends on General ARDL models, we use the two-step procedure, with a small sample of study using the algorithm:

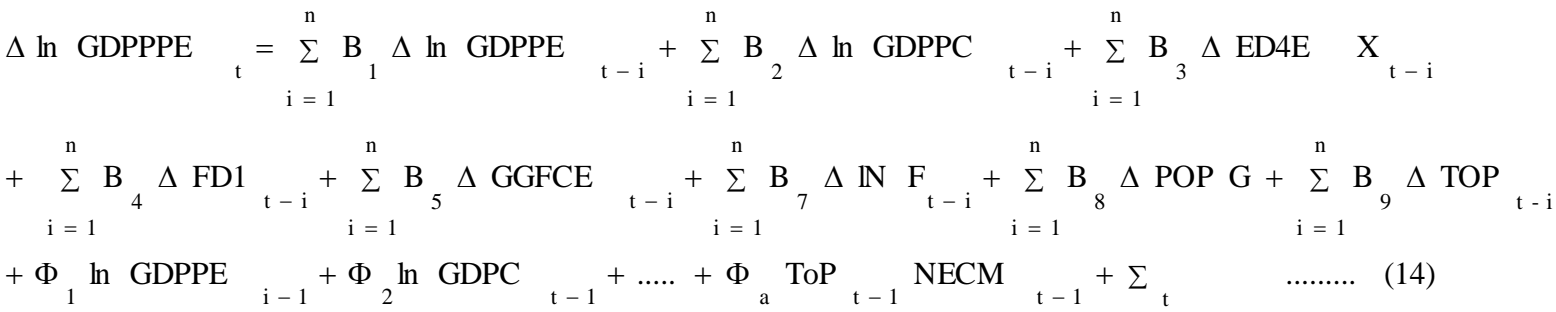

Where $\left(\mathrm{B}_{1}\right.$ to $\mathrm{B}_{9}$ ) represents the short run dynamics of the model the $\left(\Phi_{1}\right.$ to $\left.\Phi_{9}\right)$ represents long-run relationship $\mathrm{e}$ is the stochastic error with zero mean and constant variance and $\mathrm{N}$ represents the speed of adjustment parameters, which is expected to be less than zero ECM is the lagged error correction.

Section five : Empirical results:

\section{1-5 : Descriptive statics and correlation matrix:}

Due to the exhibit of a strong trend, we should choose a method to treat this trend, the logarithmic transformation of variables is the best method to do so, the result of the method is effectively laniaries the exponential trend, since the study dealing with the time series, some variables are stated in logarithmic point to avoid the cumbersomeness in the model. In table (2) illustrate the descriptive statistic of variables.

Table ( 2 ) : Descriptive statistics of Jordan inclusive growth

\begin{tabular}{|l|l|l|l|l|l|l|l|l|l|}
\hline & $\begin{array}{l}\text { Ln } \\
\text { GDPPPE }\end{array}$ & $\begin{array}{l}\text { Ln } \\
\text { GDPPPc }\end{array}$ & Edcu & FDi & GGFCE & GFCF & InF & POPG & TOP \\
\hline Mean & 3.7654 & 1.7282 & 1.345 & 2.943 & 6.545 & 8.723 & 16.543 & 2.875 & 3.684 \\
\hline St/Dev & 0.6924 & 0.5813 & 0.959 & 1.4886 & 2.987 & 5.432 & 9.325 & 0.619 & 14.97 \\
\hline Skewness & -0.587 & 0.6643 & 0.4761 & 1.013 & 0.594 & 2.018 & 1.352 & 0.076 & -2.161 \\
\hline kurtosis & 1.695 & 2.3458 & 3.6182 & 4.273 & 6.468 & 5.436 & 4.019 & 1.763 & 2.1393 \\
\hline Jerque-Bera & 3.1338 & 2.7538 & 6.992 & 16.59 & 0.274 & 21.987 & 15.24 & 2.542 & 1.684 \\
\hline Prob-level & 0.1852 & 0.1693 & 0.0019 & 0.008 & 0.274 & 0.000 & 0.003 & 0.257 & 0.485 \\
\hline observ & 15 & 15 & 15 & 15 & 15 & 15 & 15 & 15 & 15 \\
\hline
\end{tabular}

Correlation Matrices

\begin{tabular}{|c|c|c|c|c|c|c|c|c|c|}
\hline & InGGPPE & InGDPPC & EDUC & GFCE & FDI & GFCE & INF & POPC & ToP \\
\hline InGGPPE & 1 & & & & & & & & \\
\hline LnGDPPC & 0.5983 & 1 & & & & & & & \\
\hline EDUC & -0.4332 & -0.2165 & 1 & & & & & & \\
\hline FDi & 0.1385 & -0.4371 & -0.3662 & & 1 & & & & \\
\hline GFCF & -0.2653 & 0.1040 & 0.6773 & $1-0.2431$ & & & & & \\
\hline GFCE & -0.1944 & -0.1763 & & & & & & & \\
\hline \multirow{2}{*}{\multicolumn{10}{|c|}{$\begin{array}{l}\text { INF } \\
\text { POPC }\end{array}$}} \\
\hline & & & & & & & & & \\
\hline TOP & & & & & & & & & \\
\hline
\end{tabular}


The descriptive statics in table (2), shows that the growth rate of GDP product per person in Jordan and initial income per capital at $3.765 \%$ and $1.73 \%$ respectively, where the average value for the government expenditure on education, gross fixed capital information, foreign direct investment, government financial consumption, inflation population growth, and trade openness (a ratio of GDP) are 1.34\%, 2.94\%, 6.545\%, 8.7\%, 16.55\%, 2.8\%, and $58 \%$. The statistics of skewness which is measured by the asymmetry of the distribution of series around the mean indicates that all variables except GDPPPE and trade openness (TOP) are positively skewed, also the kurtosis which measures the peakedness or flatness of the distribution for the series are revealed none of the variables are normally distributed, where in skewness the implying of the variables of distribution give us a long right tail, when kurtosis for the variable reveal has a platykurtic in hence the distribution is flat relative to the normal. Where Jarque - Bera which measured whether the series is normally distributed or not, the variables; Education FD1, GFCF, and inflation rejects the null hypothesis of normal distribution and accepts the null hypothesis for $\ln$ GDPPPC, FD1, POPG, and TOP. Finally, the correlation matrix shows the relationships between and other variables such as the ln GDPPC, FD1, POPD and TOP related to positive relationships with ln GDPPPE, while other variables are negatively correlated.

\section{2 -5 : Stationary, lag length and brown test:}

The ARDL models do not impose pretesting of variables for unit root problems the ARDL cannot be estimated with 1 (2) series in this paper the ADF unit root test is implied to ensure that the series is non - stationary. While the absences of unit root give us a sign that the stochastic process is stationary. In this paper, the researcher uses the augmented Dickey-Fuller (ADF) test and Phillips Perron (PP) test to check whether a unit root of data or absence.

Table (3 ): results of the ADF test and PP for the variables of the study.

\begin{tabular}{|l|l|l|l|l|l|}
\hline Variables & $\mathbf{1}(\mathbf{0})$ ADF & PP & $\mathbf{1}(\mathbf{1})$ ADF & PP & $\begin{array}{l}\text { Order of } \\
\text { integration }\end{array}$ \\
\hline Ln e-DPPPE & -2.1674 & -2.4872 & $-4.6532^{* * *}$ & $-4.5937^{* * *}$ & $1(1)$ \\
\hline Ln GDPPC & -2.284 & $-3.1665^{* *}$ & $-5.7691^{* * *}$ & $-7.6229^{* * *}$ & $1(1)$ \\
\hline Education & $-4.9843^{* * *}$ & $-4.2365^{* *}$ & -3.1008 & $-1.3672^{*}$ & $1(1)$ \\
\hline FD1 & -2.7651 & $-3.5291^{*}$ & $-6.9637^{* * *}$ & $-10.453^{* * *}$ & $1(1)$ \\
\hline GFCF & 3.0924 & $-3.2617^{*}$ & $-5.2263^{* * *}$ & $-3.6927^{* * *}$ & $1(1)$ \\
\hline GGFCE & -2.8531 & -2.7654 & $-6.178^{* * * *}$ & $-6.234^{* * *}$ & $1(1)$ \\
\hline Inf & $-3.0924^{* *}$ & -3.1043 & $-5.8036^{* *}$ & $-9.8104^{* * *}$ & $1(1)$ \\
\hline POPG & -0.7682 & -0.4931 & $-2.1651^{* *}$ & $-4.0378^{* * *}$ & $1(1)$ \\
\hline TOP & -2.0165 & -1.9872 & $-6.3524^{* * *}$ & $-6.3952^{* * *}$ & $1(1)$ \\
\hline
\end{tabular}

Note : *,*, ***, significance at $10 \%, 5 \%, 1 \%$ level.

In the table (4 ) the optimal lag order for the ADF test is determined by Aic, while the bandwidth for Phillip peron (PP) tests are determined by Newey-west Bartlett Kernel. The results of bound testing that ln GDPPPE, ln GDPPC, GGFCE, lnf, POPG and trade; variables unit roots at level where becomes stationary at the first difference while FDI and GFCF exhibit stationary at level all variables can be characterized as $1(0)$ and 1 (1) at 5 percent significance level.

\begin{tabular}{|l|l|l|l|l|l|l|}
\hline Tag order & Log L & LR & FPE & AiC & Se & HQ \\
\hline 0 & -472.8403 & NA & 61.5932 & 29.219 & 30.1652 & 30.0871 \\
\hline 1 & -165.6352 & 336.015 & $2.03 \mathrm{e}^{-5}$ & 18.7542 & 20.6421 & 19.593 \\
\hline 2 & 119.3781 & 143.7261 & $6.61 \mathrm{e}^{-0.7}$ & $6.5394^{*}$ & $15.7851^{*}$ & 9.432 \\
\hline
\end{tabular}

Note : * significance at $5 \%$ level.

In table (4 ) results shows that both Schwartz - Bayesian Criterion (SBC) and Akaike information criterion, (AiC) are similar, thus a lag order of 2 is selected, the model of ARDL $(\mathrm{P}, \mathrm{q}, \mathrm{r}, \mathrm{s})$ used is $(\mathrm{P}+1)^{\mathrm{k}}$, where $\mathrm{k}$ is the number of variable in the equation which is (8) variables as dependent in this study .

\section{3-5: The ARDL estimation:}

1-3-5: The maximum lag length is set out by using AiC (Akaike Information Criterion and the normalized longrun coefficient which reported in the table (5) 
Table (5 ): The long-run test of normalized coefficients -panel 1

\begin{tabular}{|l|l|l|l|}
\hline Variables & Coefficients & St/ error & T - value \\
\hline ln GDPPC & Panel I, long run, $0.6879^{* * *}$ & 0.05483 & 9.5763 \\
\hline EDUC & $-0.2365^{* *}$ & 0.0386 & -2.0134 \\
\hline FD1 & 0.19734 & 0.0479 & 4.0362 \\
\hline GGFCE & $-0.07653^{*}$ & 0.0260 & -2.6531 \\
\hline CFCF & $0.0156^{*}$ & 0.0165 & 1.1765 \\
\hline Inf & $-0.0763^{* *}$ & 0.037 & -2.4522 \\
\hline POPG & $-4.3269^{* * *}$ & 0.5872 & -0.2941 \\
\hline TOP & $-0.0069^{* *}$ & -0.3489 \\
\hline
\end{tabular}

Panel 2 (Diagnostic checking)

$\mathrm{R}^{-2}=0.895, \quad \mathrm{R}$ Squared $=0.916 \quad$ LM test $=4.6327$

Jarque - Bera $=0.631 \quad(0.721)$

White : 0.872 (2.735)

Note: ${ }^{* * *}$ significance at $10 \%$ level, $\quad{ }^{* *}$ significance at $5 \%$ level

The determinate coefficient for the model is 0.916 as $92 \%$ this means that the changes independent variables due to the changes in the independent variable the coefficient parameters of ln GDPPC is 0.6879 , it means that an increase in initial capital income will cause $69 \%$ increase in inclusive growth in order in the long - run where education expenditure has a negative impact on inclusive growth in Jordan while gross fixed capital information and Trade openness do not have to describe impact on inclusive growth in the long - run, where inflation and government consumption have significant negative impact inclusive growth, while the increase of population growth by 1 percent leads to reduce the inclusive growth to $4.33 \%$. The short - run dynamic relationships can be demonstrated in a table (6).

Table (6) Error correction model (ECM)

\begin{tabular}{|l|l|l|l|}
\hline Variable & Coefficient & St. Error & t-value \\
\hline$\Delta$ (ln GDPPC) & 0.2682 & 0.1546 & 0.8776 \\
\hline$\Delta$ (ln GDPPC-1) & $-0.4733^{* *}$ & 0.1249 & -2.6382 \\
\hline$\Delta$ (EDUC) & $-0.1154^{* *}$ & 0.0538 & -2.7665 \\
\hline$\Delta$ (EDUC-1) & $-0.5676^{* *}$ & 0.0192 & 2.4334 \\
\hline$\Delta$ (FD1) & $-0.08711^{* *}$ & 0.0163 & -6.3879 \\
\hline$\Delta$ (FD1-1) & $-0.06332^{* *}$ & 0.0538 & -1.5448 \\
\hline$\Delta$ (GFCF) & 0.0103 & 0.0015 & 1.1376 \\
\hline$\Delta$ Inf & $0.0068^{* *}$ & 0.0017 & 2.9471 \\
\hline$\Delta$ (TOP) & -0.0009 & 0.0026 & -0.6382 \\
\hline$\Delta$ (POPG) & 1.1563 & 1.0782 & 1.1683 \\
\hline ECM (-1) & $-0.842^{* * *}$ & 0.1699 & -5.3672 \\
\hline
\end{tabular}

Note: ${ }^{* * *, * * *}$ shows the significance at $1 \%, 5 \%, 10 \%$ levels.

Respectively in table (6) results indicates that previous year's inclusive growth in Jordan has a negative impact on the current inclusive growth in the short run, while education expenditure of 1 percent increase will reduce the inclusive growth 0.12 , where the population growth has no significant effect on inclusive growth in the short run.

Where inflation has a positive effect on inclusive growth of Jordan, while capital for mention has no significance impact in both short - run and long - run on inclusive growth the effect of trade openness has a positive sign effect lout in significant, while the government consumption still remain negative effect one Inclusive growth.

\section{2-3-5 : The diagnostic test:}

According to the results of the model. the model passes through $\mathrm{R}^{2}=91 \%$ which shows and tends to purge the influence of number of included variables in the study, we can concluded that the model is still good , and the 
dependent variables explain the equation by $91 \%$, hence the results of good knees of fit we can say that the test is fair. In table (7) we check the diagnostic tests against serial correlation.

Table (7): Diagnostic tests results

\begin{tabular}{|l|l|l|}
\hline Tests & Results & Prob- level \\
\hline Ramsey Reset & 10.7634 & 0.0002 \\
\hline Normality test & 45.6882 & 0.0000 \\
\hline Meterostkedlasticty & 18.6357 & 0.3294 \\
\hline Breusch-Godfory: LM test & 2.8433 & 0.2963 \\
\hline
\end{tabular}

The model also passes the diagnostic tests against serial correlation, functional from misspecification and nonnormal errors all test results Ramsey test, normality and LM test are significant at 5\% levels while it failed the heteroscedasticity test at $5 \%$ level therefore the model is fair to analysis the inclusive growth.

The stability test:

3-3 - 5: The graphic investigated is recommended by Pesran and chin 1999 to the stability estimation coefficient of error correction model while represents cumulative sum (CUSUM) and cumulative sum square (CUMSUMQ) of the recursive residual. When we demonstrate that in short-run model which passed the diagnostic tests, and there is no evidence of auto correlation at 5\% significance level and passes the normality test both the (CUM SUM) and (CUM SUM Q) for the recursive residual will prove the stability of the long-run coefficients for the regressors that have an effect on inclusive grow of Jordan. figure 6 and 7 ,declare this.

Figure ( 6 ) The cumulative sum (CUM SUM)

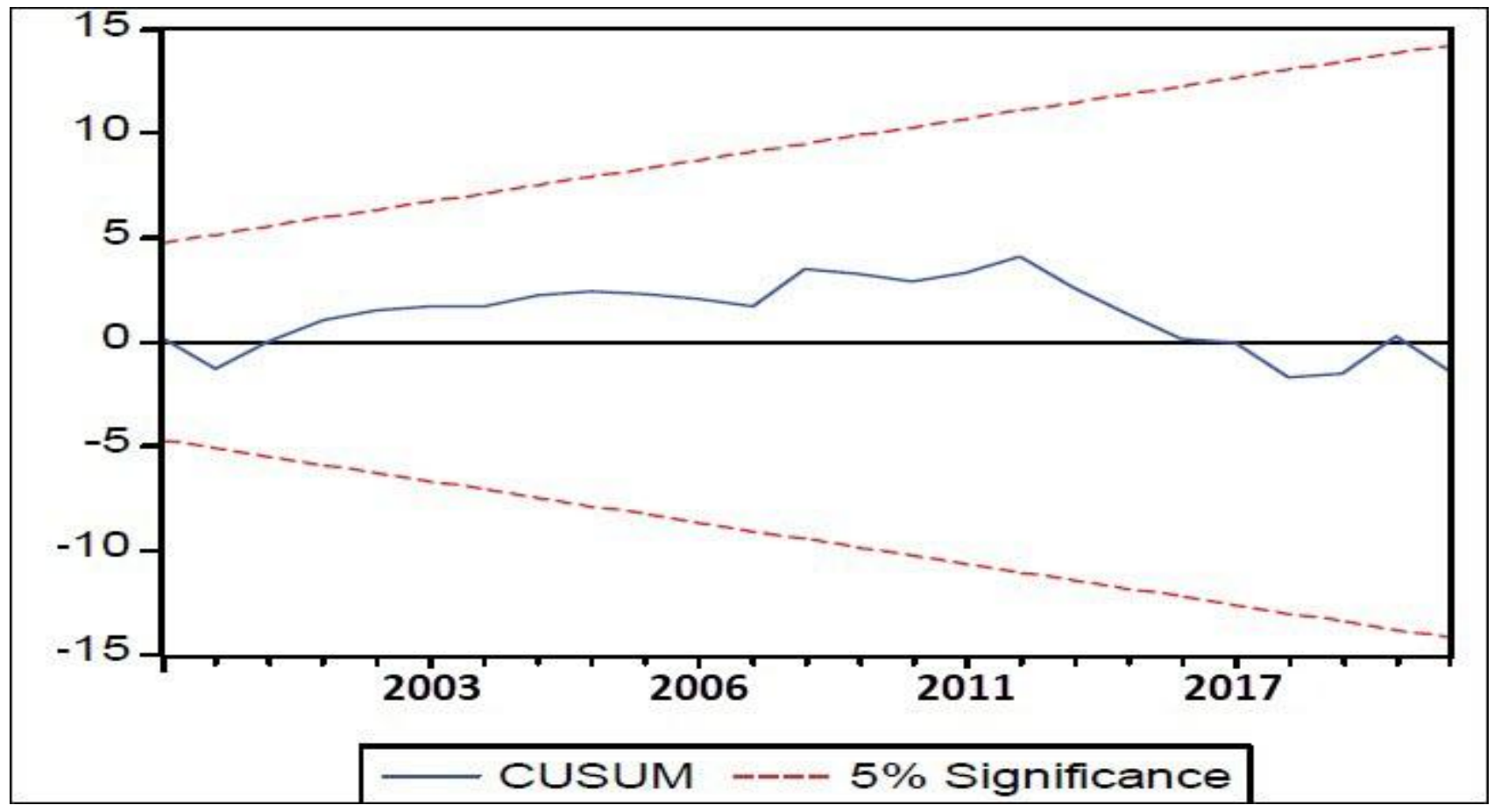


Figure (7): (CUM SUM Q) for the recursive residual

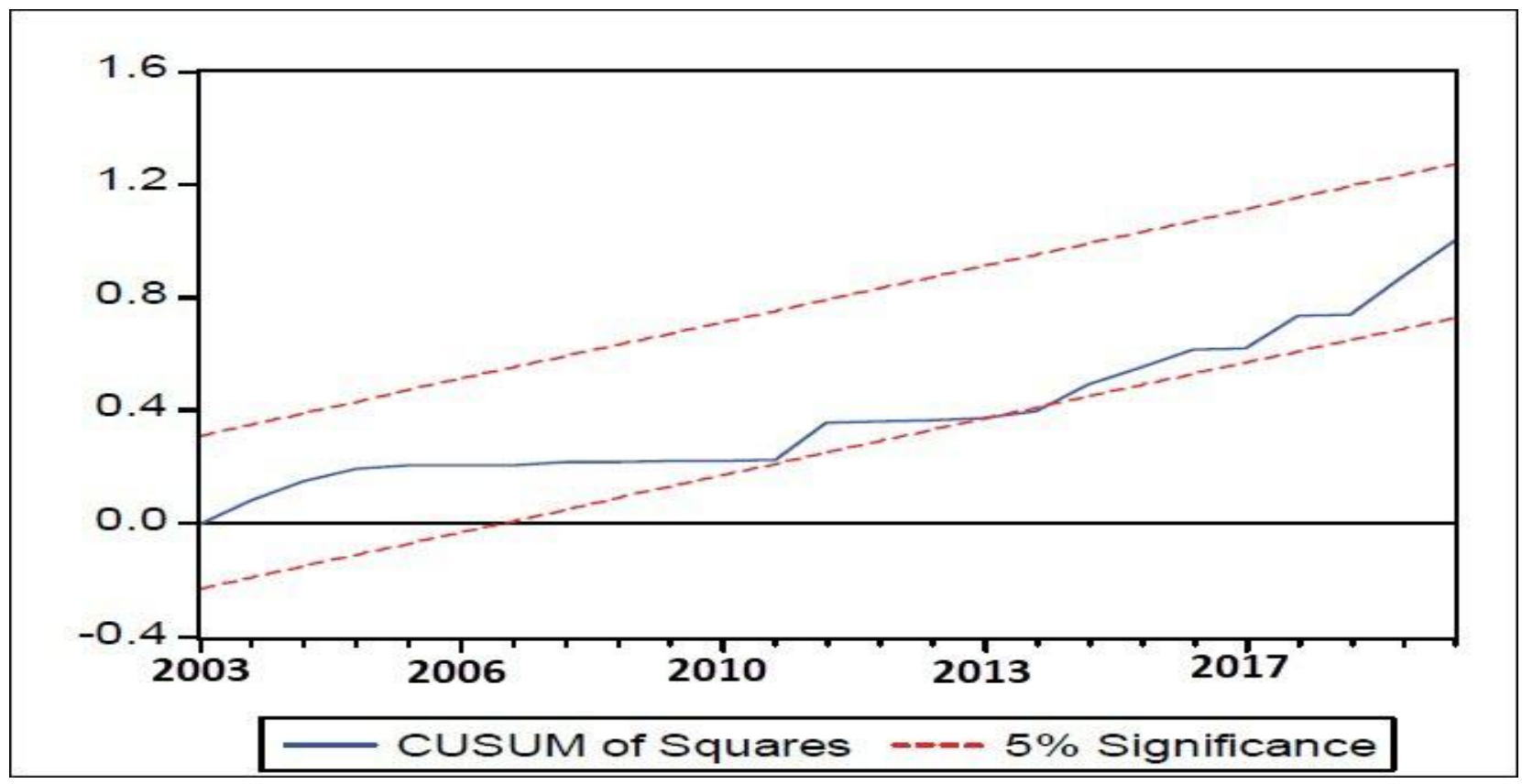

\section{Conclusion}

The inclusive growth prospect in Jordan is an important and has great concern to policy maker in Jordan, also the donors of aids who help Jordan. In this paper, we can say that the important determinant variables of inclusive growth in Jordan are: foreign direct investment, Trade openness government consumption, information, GDP volatility, infrastructure quality, human capital, population growth thus we adopt the ARDL Traditional model to analyze the data which is predicted the social opportunity function. This paper utilized of bounds test of ARDL approach to cointegration to examine the long run relationship between independent variable GDPPPE variable and the explanatory variables, the bound test suggest that the variables which declare in the framework are bound to gather in long-run, also ECM test was significance confirming the existence of the long-run relationship.1The result of this paper corroborates the finding of many scientists such as Liu et. al, (2008), Maku, (2009) and others which suggest that government expenditure should be increased (spending) due to sustainable growth, also productivity should be increased, beyond the budget implementation should be monitored for effective performance other policy can be encourage and in Jordan, that population growth should be monitored and control are recommendation as results of our finding of this paper that government should work at improving macroeconomic stability, and the policy maker should be considered many directions such as reduce the inflation rate by embarking on tight fiscal and monetary policy and improving the quality of the population through developing policy of education and health, which can encourage the innovative and improve the technology advancement which needs to inclusive growth.

\section{References}

A Gasparini, F Scheipl, B Armstrong, and M G Kenward. A penalized framework for distributed lag non-linear models. Biometrics, (In Press), 2017.

Abdulai A. (2002). Using threshold cointegration to estimate asymmetric price transmission in the Swiss pork market. Applied Economics, 34, pp. 679-687.

Ahn, S. K. and G. C. Reinsel (1990). Estimation for partially no stationary multivariate autoregressive models. Journal of the American Statistical Association 85(411), 813\{823.

Ali I, Zhang J. Inclusive growth toward a prosperous Asia: policy implications. Manila, Asian Development Bank; 2007.Available from http://catalog.hathitrust.org/api/volumes/ oclc/1 83261384.html [Accessed 15th December 2016].

Asian Development Bank. The framework of Inclusive Growth: Key Indicators for Asia and the Pacific; 2013. Available from http://siteresources.w orldbank.org/INTDEBTDEPT/Resources/468980-12185678 
Budgeting, Accounting, and Financial Management. economic growth: The Granger causality test of the US Data, 1974-2002". Journal of Public gator), North Holland.

Chao, J. C. and P. C. B. Phillips (1999). Model selection in partially no stationary

D. Hendry and G. Mizon, Serial Correlation as a Convenient Simplification, not a Nuisance: A Comment on a Study of the Demand for Money by the Bank of England. Economic Journal, 88, (1978), 349-363.

Dhaene, G. and Jochmans, K. 2015. "Split-panel jackknife estimation of fixed-effect models." Review of Economic Studies, forthcoming.

Gasparrini A, Armstrong B, Kenward MG. Distributed Lag Non-Linear Models. Statistics in Medicine. 2010; 29 (21): 2224-2234. [PMC free article] [PubMed]

Greene, W. H. (2012). Econometric analysis (7th ed.). Upper Saddle River, N.J: Prentice Hall. growth in Thailand". Journal of Economics and Economic Education Research, Vol.

Gujarati, D. N., and Porter, D. C. (2010). Essentials of Econometrics (4th ed.). New York: McGraw-Hill/Irwin.

Hendry, D., A. Pagan and J. Sargan (1984),.Dynamic Speci.cations. Chap- Hinkley, D.V. 1969. "On the Ratio of Two Correlated Normal Random Variables." Biometrika, Vol. 56 No. 3, pp. 635-639.

India: A re-examination". The IUP Journal of Public Finance.

India". The ICFA/University Journal of Public Finance, Vol. 6(3): 60-69 jae.616

Komain, J. and Brahmasrene, T. (2007). "The relationship between government expenditures and economic

Liu Chin, H.L., Hsu, C. and Younis, M. (2008). "The association between government expenditure and McKinley Terry (2010) Inclusive Growth Criteria and Indicators: An Inclusive Growth Index for Diagnosis of Country Progress ADB Sustainable Development WP series No.14.MPRA Paper no. 17941.

Maku, O.E. (2009). "Does Government Spending Spur Economic Growth in Nigeria? Munich Personal 8(1), pg

93-104. 84549/WhatIsInclusiveGrowth20081230.pdf [Accessed 10 ${ }^{\text {th }}$ January 2017]. 99-125.

Mason, Ohio: South-Western Cengage Learning.

Peltzman S. (2000). Prices rise faster than they fall. The Journal of Political Economy, 108, pp. 466-502.

Pesaran H. M, Shin Y. and Smith R.J (2001): "Bounds Testing Approaches To The Analysis Of Level

Phillips, P.C.B. and B. Hansen (1990),.Statistical Inference in Instrumental

R. Engle, and G. Granger, Cointegration and Error Correction: Representation, Estimation and Testing, Econometrica, 55, (1987), 251-276.

Ranjan, K.D. and Sharma, C. (2008). "Government expenditure and economic growth: Evidence from Relationships". Journal of Applied Econometrics. Econ. 16: 289-326 (2001). DOI: 10.1002/

RePEc Archive. Retrieved on 13/8/2010 from http://mpra.ub.uni-muenchen.de/17941/

Sakthivel, P.and Yadav, I.S. (2005). "Causality between public expenditure and national income inter 18 in Handbook of Econometrics, Vol II (ed., Z. Griliches and M. Intrili-Variables Regression with I(1) Processes, Review of Economic Studies, 57: vector autoregressive processes with reduced rank structure.Journal of Econometrics 91, 227\{271.

Wooldridge, J. M. (2012). Introductory Econometrics: A modern approach (5th ed.).

World Bank. "What is Inclusive Growth?”. World Bank, Washington DC; 2009. 